\title{
Power Distribution Optimization Based on Demand Respond with Improved Multi-Objective Algorithm in Power System Planning
}

\author{
Oveis Abedinia * and Mehdi Bagheri (D) \\ Department of Electrical and Computer Engineering, School of Engineering and Digital Sciences, \\ Nazarbayev University, Kabanbay Batyr Ave. 53, Nur-Sultan 010000, Kazakhstan; mehdi.bagheri@nu.edu.kz \\ * Correspondence: oveis.abedinia@nu.edu.kz
}

Citation: Abedinia, O.; Bagheri, M. Power Distribution Optimization Based on Demand Respond with Improved Multi-Objective Algorithm in Power System Planning. Energies 2021, 14, 2961. https://doi.org/ $10.3390 /$ en14102961

Academic Editor:

Mohamed Benbouzid

Received: 11 April 2021

Accepted: 17 May 2021

Published: 20 May 2021

Publisher's Note: MDPI stays neutral with regard to jurisdictional claims in published maps and institutional affiliations.

Copyright: (c) 2021 by the authors. Licensee MDPI, Basel, Switzerland. This article is an open access article distributed under the terms and conditions of the Creative Commons Attribution (CC BY) license (https:// creativecommons.org/licenses/by/ $4.0 /)$.
Abstract: In this article, a novel dynamic economic load dispatch with emission based on a multiobjective model (MODEED) considering demand side management (DSM) is presented. Moreover, the investigation and evaluation of impacts of DSM for the next day are considered. In other words, the aim of economical load dispatch is the suitable and optimized planning for all power units considering different linear and non-linear constrains for power system and generators. In this model, different constrains such as losses of transformation network, impacts of valve-point, rampup and ramp-down, the balance of production and demand, the prohibited areas, and the limitations of production are considered as an optimization problem. The proposed model is solved by a novel modified multi-objective artificial bee colony algorithm (MOABC). In order to analyze the effects of DSM on the supply side, the proposed MODEED is evaluated on different scenarios with or without DSM. Indeed, the proposed MOABC algorithm tries to find an optimal solution for the existence function by assistance of crowding distance and Pareto theory. Crowding distance is a suitable criterion to estimate Pareto solutions. The proposed model is carried out on a six-unit test system, and the obtained numerical analyses are compared with the obtained results of other optimization methods. The obtained results of simulations that have been provided in the last section demonstrate the higher efficiency of the proposed optimization algorithm based on Pareto criterion. The main benefits of this algorithm are its fast convergence and searching based on circle movement. In addition, it is obvious from the obtained results that the proposed MODEED with DSM can present benefits for all consumers and generation companies.

Keywords: multi-objective optimization; artificial bee colony; dynamic economic and emission dispatch; demand side management; load shifting

\section{Introduction}

Electrical energy has particular downsides such as high cost, being time consuming, etc., and it is gradually is being replaced by other energies as a result. In recent years, many causes such as increasing electricity generation cost, the uncertainty growth of load consumption, the global increase of fuel cost, restrictions in the environment, determining the place of powerhouses, etc., have drawn important attention toward the logical growth of electricity consumption [1].

Therefore, the demand side management (DSM) of electricity consumption in recent years is considered one of the best and vital methods of maintaining common profits between the electricity industry and electrical energy consumers. DSM as a fundamental subject tries to change load consumption at peak-time to the form of long-term in dedicating resources regarding its numerous profits for both sides of the electricity industry and consumers [2,3]. Hereby, the power markets have paid significant attention to the programs of DSM due to their benefits in financial and load profile [4]. DSM not only helps the electricity industry and consumers, furthermore, it has effective benefits for generation 
companies. The implementation of DSM in electricity networks requires updated information and technologies. These technologies make a two-way connection between the electricity's suppliers and consumers. Therefore, the smart controlling and the measuring tools of central energy are used for their dynamic interaction. Dynamic bidding policies include time of use (ToU), division of the critical peak time, on-time bidding, the least off-peak time, and bidding for the next days of smart bidding tools in the process of DSM implementation [5-8]. According to recent papers, three types of DSM commonly are used: environmental, network, and market. DSM with the environmental option commonly concentrates the standards on environmental and social areas such as decrease of greenhouse gasses' emissions. DSM by using the network option aims to maintain the certainty of the network, and the aim of DSM is to trigger the financial frugality of public facilities and consumers [9]. The overall view of the suggested demand side management (DSM) is shown in Figure 1.

Service Provider domain

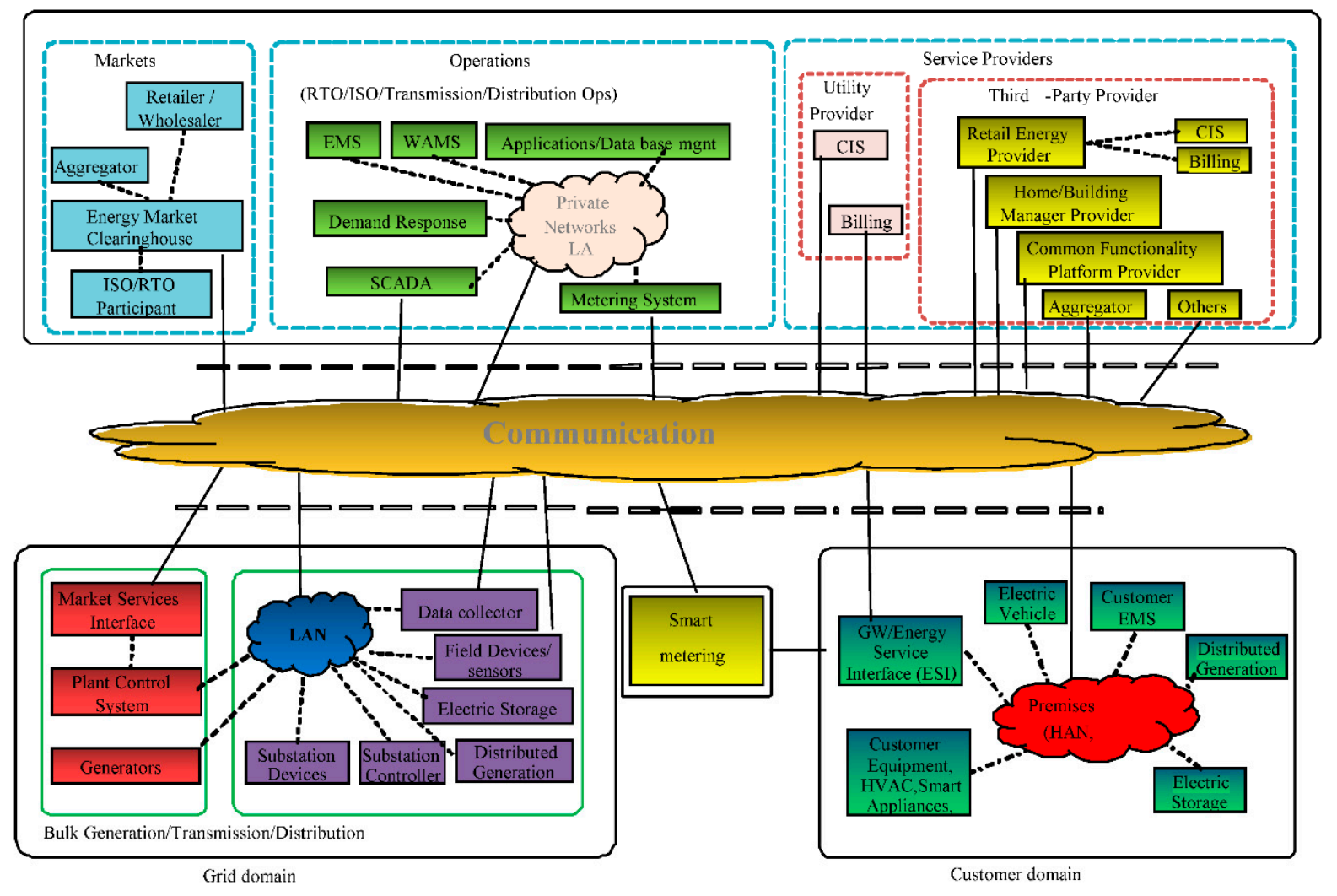

Figure 1. Suggested demand side management (DSM) of this article.

In [10], a new integrated method of multi-objective dynamic economic and emission dispatch (MODEED) is presented by implementing demand side management (DSM) in order to consider the advantages of presented DSM on the group side. The presented method investigated the upcoming day on the basis of load changing and the DSM method.

In [11], the authors implemented genetic algorithm to solve the problem of DSM and dynamic economic dispatch (DED). The authors had deliberated the issues of DSM and DED in two interrelated levels during the optimization procedure. In fact, it had used load profile for each individual consumer. Thus, they used Genetic Algorithm (GA) in order to find out the enhanced problem to introduce electrical tools for consumers.

Lorenthiran et al. [12] implemented the DSM technique of load profile based on the next day in the environment of smart network with the assistance of a discovering algorithm. The energy control strategy is developed for load demand management at peak times [13]. Another algorithm for energy management is suggested by Ma et al. [14] to 
access the bidding strategies and consumers' functional states. Dynamic emission and economical dispatch (DEED) are considered in the operation and control of an electricity network. The DEED in online production presents the predicted load demand period, which is done by minimizing the cost and emission simultaneously. Altinoz et al. [15] investigated a type of financial or emission load model based on the transmitting issue. The suggested model considered non-synchronous and reserved producers to varied demanding zones, which it contradicted with previous transmitting issues. Among them, only a few of the producers are considered for the demanding zones. Consequently, during the process, each producer has an effect over the other producers. In addition, the suggested model is enhanced by generated energy that could be purchased by other close locals. From the point that most of the dimensions, restrictions, and aims are presented within the provided model, it declines the frequency of aims. Alham et al. [16] recommended a novel DEED with wind power regarding the feature of intermittency and ambiguity. They used an energy storage system (ESS) and DSM in order to investigate the effect of charge, discharge, and the use of wind power.

In order to solve the EED, the GAMS software was used. The obtained results demonstrated the significance of applying ESS and DSM in declining the charge and discharge rate and raising the wind power consumption. Dehnavi et al. [17] evaluated TOU on the demand side by combining the problem of DED, which considers the supplier side. Zaman et al. [18] combined an algorithm of DE and GA for solving the issues of DEED by considering different generator units such as thermal, solar-thermal, and wind. The problem of DEED based on the developed PSO and wind's uncertainty is presented by Aghaei et al. [19].

In [20], new combined framework-based electric vehicles and wind farms are suggested for solving the dynamic economic emission dispatch problem. In [21], the authors presented the combination of renewable energy sources to a multi-objective DEED problem in a day through minimizing the energy cost and emission as well. In [22], the DEED problem is solved as a non-linear and complex objective based on a combined Flower Pollination Algorithm (FPA) with Sequential Quadratic Programming (SQP) algorithm. The authors in [23] provide MODEED for renewable anergy sources i.e., wind-solar-hydro power under tradable green certificates.

To cover the gap of economic load dispatch with demand side management, this article suggests a method of MODEED and DSM program based on next day for residential loads. In this suggested model, we had considered the benefit of consumers by presenting different time delays for all manageable demand with related lifestyle. The suggested model significantly focused on advantages of DSM programs in order to accommodate the supplier side with different residential load levels. In addition, in this paper, an enhanced multi-objective artificial bee colony (MOABC) based on entropy, arrangement, and fuzzy selection is proposed to minimize the MODEED simultaneously with DSM.

The rest of this paper is organized as follows. Section 2 explains the formulation of the DEED problem and DSM. The suggested integrated method is presented in Section 3. Section 4 presented the suggested improved multi-objective artificial bee colony algorithm. In Section 5, some different test systems are presented. The numerical analysis and their comparisons are presented in Section 6. At the last section, the conclusion is presented.

\section{The Problem Formulation}

\subsection{Proposed Multi-Objective Problem}

This multi-objective problem is the vital optimization challenge in the electricity network operation and control for enhancing social and economic dimensions. In the DEED problem, the total fuel cost and emission cost should be minimized simultaneously [24]:

$$
F_{1}=\sum_{t=1}^{\tau} \sum_{g=1}^{G} C_{g, t}\left(P_{g, t}\right)
$$




$$
F_{2}=\sum_{t=1}^{\tau} \sum_{g=1}^{G} E_{g, t}\left(P_{g, t}\right)
$$

$F_{1}$ and $F_{2}$ are the total costs of fuel and the emission of the gth generator unit at time $\tau$. $C_{g, t}$ and $E_{g, t}$ are the price and pollution functions through time $t$ and $P_{g, t}$ is the output of the $g$ th generator at unit time $t$. The fuel cost function is modeled by the effect of the valve point, and the total rate of gases such as $\mathrm{NO}_{\mathrm{x}}$ and $\mathrm{SO}_{\mathrm{x}}$ are modeled as the sum of quadratic expressions:

$$
\begin{gathered}
C_{g, t}\left(P_{g, t}\right)=a_{g} P_{g, t}^{2}+b_{g} P_{g, t}+c_{g}+\left|e_{g} \sin \left(e_{g}\left(P_{g}^{\min }-P_{g, t}\right)\right)\right| \\
E_{g, t}\left(P_{g, t}\right)=\left(\gamma_{g} P_{g, t}^{2}+\beta_{g} P_{g, t}+\alpha_{g}\right)+\xi_{g} \exp \left(\lambda_{g} P_{g, t}\right)
\end{gathered}
$$

where $c_{g}, b_{g}$, and $a_{g}$ are the of fuel cost coefficients of the $g$ th generator unit and $e_{g}$ and $d_{g}$ are the valve point effect coefficients. $\gamma_{g}, \beta_{g}, \alpha_{g}$, and $\lambda_{g}$ are emission coefficients of the gth generator unit.

\subsection{Constrains}

The problem of DEED optimization has different equality and inequality constrains as follows:

(i) Power balance

$$
\sum_{g=1}^{G} P_{g, t}-P_{D, t}-P_{L, t}=0, \forall t \in\{1,2, \ldots, \tau\}
$$

$P_{L, t}$ and $P_{D, t}$ are the transmission power loss and total load demand power in the $t$ th time, respectively. $P_{L, t}$ could be calculated by:

$$
\sum_{g=1}^{G} \sum_{j=1}^{G} P_{g, t} B(g, j) P_{j, t}
$$

where $B(g, j)$ denotes the coefficient of transmission power loss. $P_{g, t}$ and $P_{j, t}$ are the real electricity outputs of the $g$ th and $j$ th generator unit at the $t$ th time, respectively.

(ii) Generation boundary

This inequality constrain can be modeled by:

$$
P_{g}^{\min } \leq P_{g, t} \leq P_{g}^{\max }, \forall g \in\{1,2, \ldots, G\}
$$

where $P_{g}^{\max }$ and $P_{g}^{\min }$ describe the lower and higher values for power output in the $g$ th generator unit.

(iii) Ramp-up and Ramp-down

This inequality constrain can be modeled by:

$$
\begin{gathered}
P_{g, t}-P_{g, t-1} \leq U R_{g}, \forall g \in\{1,2, \ldots, G\} \\
P_{g, t-1}-P_{g, t} \leq D R_{g}, \forall g \in\{1,2, \ldots, G\} .
\end{gathered}
$$

Therefore, the above equations can be rewritten as:

$$
\max \left(P_{g}^{\min }, P_{g, t-1}-D R_{g}\right) \leq P_{g, t} \leq \min \left(P_{g}^{\max }, P_{g, t-1}+U R_{g}\right)
$$

where $U R_{g}$ and $D R_{g}$ are the upper and lower ramp bound rates of the $g$ th of generation unit. They show that increasing or decreasing the output powers for thermal production units is a time-consuming action. 


\subsection{Problem of Demand Side Management}

The strategies of DSM mostly are needed for public facilities in order to grow their economics and develop a demand shape. Typically, companies of public industry have interesting DSM methods for encouraging the higher incorporation of consumers. Therefore, the public industry companies could easily succeed in reaching their aims. According to recent papers that address the DSM problem, the clipping of peak, filling the path, load shifting, strategic consideration, growth of strategic demand, and supple load curve are considered as the six main approaches [7]. The first three approaches are basic levels and the others are innovative methods that monitor the total load curve by either limiting or extending.

The load shifting method is the sum of two restricting peak and filling path methods, and it is considered the best method among the all demand management approaches. The demand-shifting model could be applied by controllable demands in the user side. In this mode, the controllable demands shift from peak time to off-peak, excluding any change in consuming power. The six methods of DSM are illustrated in Figure 2.

d) Flexible Load Shape

a) Peak Clipping

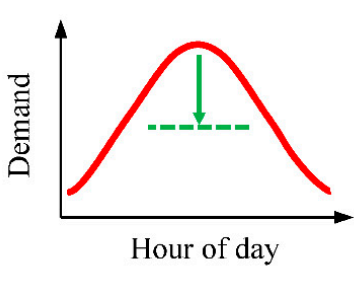

b) Valley Filling

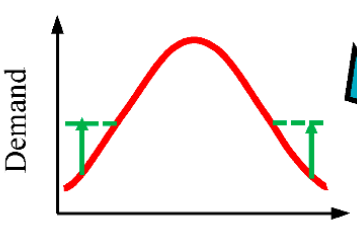

Hour of day
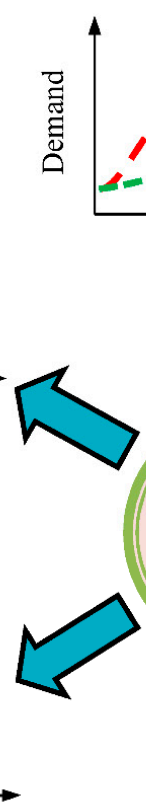

c) Load Shifting

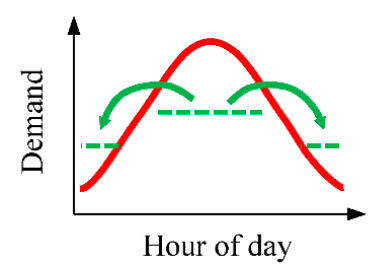

e) Strategic Growth

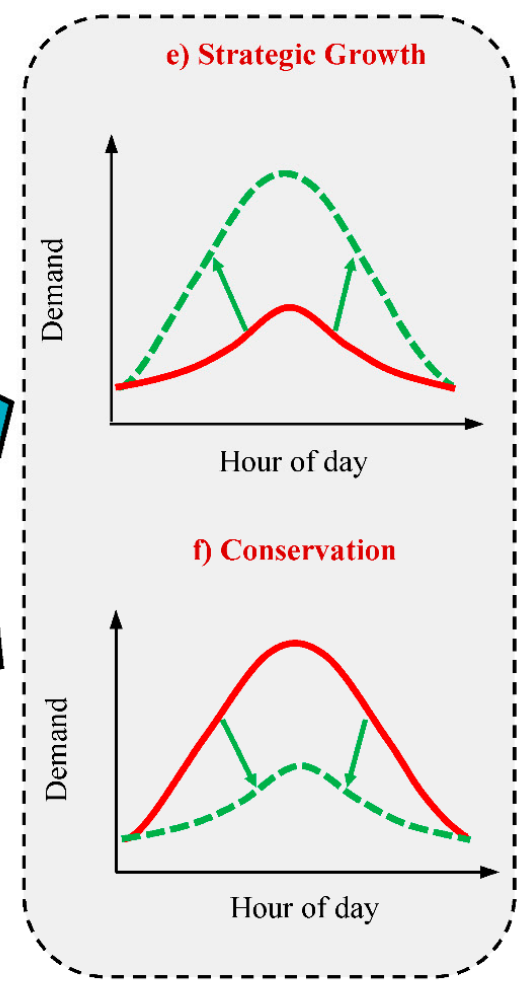

Figure 2. Overall view of DSM methods.

The DSM technique of load shifting based on the next day is used in this paper in order to investigate its impacts on the production side. This paper considers minimizing the bill of public energy as a basic aim for implementing DSM. Therefore, the prediction curve of load demand is estimated based on previous data. Consequently, the price signal is dedicated for each unique load, and the public company creates an aim load shape that is contrary with separate values. During the previous day, the DSM central controller receives an aim load shape as an input and computes the controlling measurements of ideal demand consumptions. Regarding the obtained results, the controlling measurements were 
conducted in ON time periods. During ON time operations, when the consumer sends the request connection of a device via bottom ON over the domestic devices, DSM controls or permits the attachment or provides another attachment time. The total ON time procedure is conducted efficiently by using mutual information and connection technologies. The total sell price of the electricity market of each individual break is dedicated by the ToU tariff approach, which is one of the methods of pricing tools. In the ToU tariff model, the pricing of the critical peak and lower price for off-peak periods are evaluated. According to theses pricing tools, DSM members want to place their plans in off-peak periods. The DSM can be controlled by electricity consumption patterns. In this paper, the aim of DSM with the suggested algorithm is discovering an optimized solution.

\section{Utility Energy Modeling of DSM}

The critical purpose of public industry power bill function is decreasing the space of the predicted load demand curves and aimed load demand trend through the controllable loads. The proposed function is formulated as follows:

$$
\min F=\sum_{t=1}^{\tau}(\psi(t)-\xi(t))^{2}
$$

where $\xi(t)$ and $\psi(t)$ are the quantities of aimed load demands and the load after timing DSM at period $t$. $\tau$ denotes the numbers of existence total time in load demand profile in a day. The suggested flowchart is demonstrated in Figure 3.

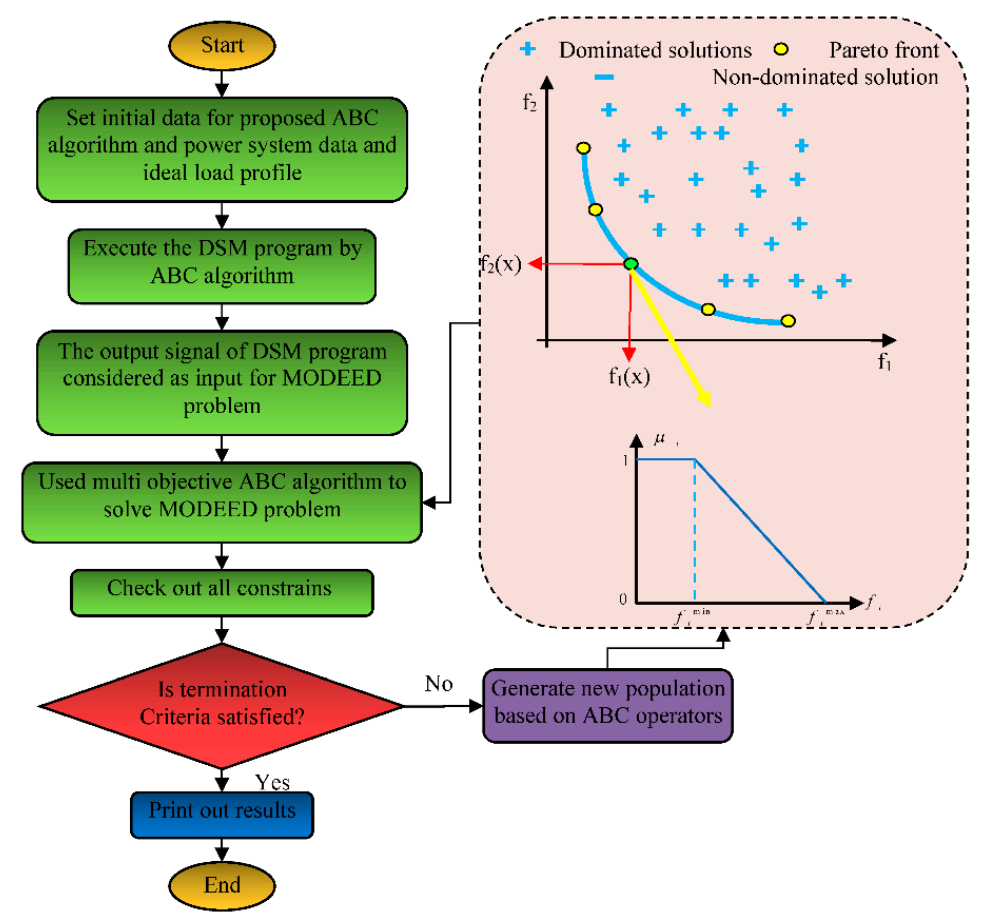

Figure 3. Simplified flowchart of compound DSM and MODEED models.

According to above equation, the $\psi(t)$ can be computed as follows:

$$
\psi(t)=F L(t)+C L(t)-D L(t)
$$


where $F L(t)$ is the quantity of the predicted load at period $t, C L(t)$ and $D L(t)$ are the quantities of attached load demands and shut-off during demand shifting at period $t$. It is calculated as follows:

$$
C L(t)=\sum_{i=1}^{t-1} \sum_{l=1}^{N} X_{l i t} \cdot P_{1 l}+\sum_{j=1}^{t-2} \sum_{k=j+1}^{t-1} \sum_{l=1}^{N} P_{(t-k+1) l} .
$$

$X_{l i t}$ is the amount of $l$ manageable domestic devices that is changed from $i$ to $t$ time, $N$ is the total type of controllable domestic devices, $P_{1 l}$ and $P_{(t-k+1) l}$ are the electricity load consumption due to the change device of $l$ type and time steps $(t-k+1)$. Here, the $(t-k+1)$ is the time step of electricity consumption with device type 1 in $t$ time, which is changed from $j$ to $k$.

$$
D L(t)=\sum_{q=t+1}^{t+m} \sum_{l=1}^{N} X_{l t q} \cdot P_{1 l}+\sum_{j=1}^{t-1} \sum_{k=j+1}^{j+m} \sum_{l=1}^{N} P_{(t-j+1) l}
$$

where $X_{l t q}$ is the number of controllable domestic devices from type 1 that had changed from $t$ time to $q$ period and in addition, the delayed maximized steps of $m$ have the ability to manage the controllable domestic devices. For the load-shifting process, the following constrains should be considered for load management:

$$
\begin{aligned}
& X_{l i t}>0, \forall l, i, t \\
& \sum_{t=1}^{r} X_{l i t} \leq \operatorname{Ctrd}(i)
\end{aligned}
$$

where the Ctrd (i) is the total number of controllable domestic devices from type 1 in time $t$. The other overall conditions are provided as follows:

$$
\begin{gathered}
P_{(t-k+1) l}=0, \forall(t-k+1)>D \\
X_{l i t}=0, \forall i>t . \\
X_{l i t}=0, \forall(t-i)>m
\end{gathered}
$$

where $D$ depicts the whole time period. Equation (18) presents that the DSM approach only has the delayed feature and it is not of advanced type. Equation (19) is the indicator of maximized $\mathrm{m}$ delayed for all domestic devices. In this paper, we had provided solutions to the multi-objective optimization model with the non-dominated sort and fuzzy tools. At this point, a linear membership function $u_{i, k}$ ( $k$ th objective function, $i$ th solution) is proposed for each of the objective functions $F_{i}$ as follows:

$$
\begin{aligned}
& u_{i, k}= \begin{cases}\frac{F_{k}^{\max }-F_{i, k}}{F_{k}^{\max }-F_{k}^{\text {min }},}, F_{k}^{\max }>F_{i, k}>F_{k}^{\min } \\
1, \quad F_{k}^{\min } \geq F_{i, k} \\
0, \quad F_{i}^{\max } \leq F_{i, k}\end{cases} \\
& u_{i}=\frac{\sum_{i=1}^{o} u_{i, k}}{\sum_{k=1}^{s} \sum_{i=1}^{o} u_{i, k}}
\end{aligned}
$$

where $O$ and $S$ denote the number of objective functions and non-dominated solutions, respectively. $F^{\min }{ }_{k}$ and $F^{\max }{ }_{k}$ are the minimum and maximum of $F k(X)$ of the $k$ th objective function, while $u$ is the quantity of the $k$ th objective function. The maximized quantity of $u$ makes a decision about the ultimate solution of the multi-objective problem. 


\section{Improved Multi-Objective Artificial Bee Colony Algorithm}

The artificial bee colony ( $\mathrm{ABC}$ ) has been proposed by Mr. Karaboka [25]. To improve the classic version of $A B C$, a chaotic version of this model is considered in this paper. The ergodicity and randomness specifications of chaos can understand a local deep search. An optimal local optimized ability is provided by looking for the space near superior individuals. The concept of a chaotic system can strengthen the local search ability. The restrictions of this region are determined by system parameters. Based on other features of chaos systems, they are looking at a particular area of primary conditions. In this paper, the mentioned improvement is presented by the following steps. First, the riotous coefficient appropriate with the determined region and the number of variables are generated. Then, the chaotic variables of the next iteration are calculated and then converted into decision variables. Finally, if the new results are better than the initial one/reach max iteration, they replace it as the final answer; otherwise, go to step 2. This paper had used the features of a riotous system to find ideal weights. The logistic function is a non-linear function and has one control parameter:

$$
x(k+1)=A x(k)(1-x(k))
$$

where $x(k)$ shows the system condition and $A$ is a constant value. This function intensively depends on the parameter $A$. By changing $A$, this function shows behaviors such as (from periodic). By putting $A=4$ in the equation, the logistic function shows chaos behavior. From the point of formulation, the riotous coefficient appropriate with a determined region and the number of variables $(\mathrm{Ng})$ are:

$$
\begin{gathered}
X_{c l s}^{0}=\left[X_{c l s, 0}^{1}, X_{c l s, 0}^{2}, \ldots, X_{c l s, 0}^{N g}\right]_{1 \times N_{g}} \\
c x_{0}=\left[c x_{0}^{1}, c x_{0}^{2}, \ldots, c x_{0}^{N g}\right], \\
c x_{0}^{j}=\frac{X_{c l s, 0}^{j}-X_{j, \min }}{X_{j, \max }-X_{j, \min }}, j=1,2, \ldots, N g
\end{gathered}
$$

So, we achieve:

$$
\begin{aligned}
X_{c l s}^{i} & =\left[X_{c l s, i}^{1}, X_{c l s, i}^{2}, \ldots, X_{c l s, i}^{N g}\right]_{1 \times N_{g}{ }^{\prime}}, i=1,2, \ldots, N_{c h a o s} \\
x_{c l s, i}^{j} & =c x_{i-1}^{j}\left(X_{j, \max }-X_{j, \min }\right)+X_{j, \min }, j=1,2, \ldots, N_{g}
\end{aligned} .
$$

where $X_{c l s}^{0}$ is the obtained primary place for the chaos variable. $X_{j, \min }$ and $X_{j, \max }$ are the lower and upper values of the chaos variable. $N_{\text {chaos }}$ is the number of chaos variables, respectively. On the other hand, the study and investigations of artificial bee colony show that while the particles are leading by $g_{\text {best }}$, they will have better total searching. In the artificial bee colony algorithm, the investigation is done on the basis of worker bees, and it is not utilized from the obtained best solution in each stage. Based on this principle, the standard equation of bee colony algorithm (25) is changed to Equation (26):

$$
\begin{gathered}
v_{i j}=x_{i j}+\phi_{i j}\left(x_{i j}-x_{k, j}\right) \\
v_{i j}=x_{i j}+\phi_{i j}\left(x_{i j}-x_{k, j}\right)+\lambda_{i j}\left(g_{b e s t i}-x_{i j}\right)
\end{gathered}
$$

where $\phi_{i j}$ and $\lambda_{i j}$ are the random numbers between $(-1,1)$. In comparison to the other optimization methods, the proposed methods have the following significant benefits:

- Unlike other traditional methods, this method does not need differentiation.

- Less sensitivity to the nature of the objective function means that it has convexity and continuity.

- Unlike other methods, it needs less adjustment of parameters.

- Has the ability to escape from local solutions.

- It is easily implemented and planned with other mathematical and logical operations.

- For objective function with random nature, it could be applied. 
The proposed algorithm can be followed in the below steps:

1. Generate the initial solutions $X_{i j}$

2. Compute the initial solutions in objective function

3. Initial iteration circle $=1$

4. Supply new solutions based on Equation (26)

5. Select the best resource or best answer between $X_{i j}$ and $V_{i j}$

6. Calculate the possibility rate for $X_{i j}$ solutions based on:

$$
P_{i}=\frac{f_{i t_{i}}}{\sum_{i=1}^{S N} f i t_{i}} .
$$

Indeed, to achieve appropriate solutions, one gets:

$$
f_{i t}=\left\{\begin{array}{c}
\frac{1}{1+f_{i}}, f_{i} \geq 0 \\
1+\left|f_{i}\right|, f_{i}<0
\end{array} .\right.
$$

The solutions of $P_{i}$ are between $(-1,1)$.

7. Generate new solutions $V_{i}$ based on $\mathrm{ABC}$ operator from solutions $\mathrm{X} i$ and determine their possibility rate $P_{i}$.

8. Select the best solutions between the answers of $X_{i j}$ and $V_{i j}$.

9. Determine the distorted resources and substitute the random resources with created random resources by scout bee $X i$ by:

$$
\mathrm{x}_{\mathrm{ij}}=\min _{j}+\operatorname{rand}(0,1) \times\left(\max _{j}-\min _{j}\right) .
$$

10. Save the best solution (the most qualified resource) that is obtained in this stage.

11. Cycle $=$ cycle +1 .

12. Repeat the previous stages until arriving at the stop criterion.

For modeling the suggested method, let $X$ be an n-dimension key of the search space through the decision-making vector $X=\left\langle x_{1}, x_{2}, x_{3}, \ldots, x_{n}\right\rangle$ and $X^{*}$ be the optimized result of the fitness $f(x)=\left[f_{1}(x), f_{2}(x), \ldots f_{k}(x)\right]$ for which the non-linear condition of $g_{i}(x) \geq 0, i=1,2, \ldots, m$ and the $P$ linear provision of $h_{i}(x)=0, i=1,2, \ldots, p$ are set. In the procedure of the suggested approach, all functions based on Pareto criteria are connected together. It can be noted that the problem of optimization could be converted to a maximized problem of optimization and vice versa:

$$
\begin{aligned}
& \min \operatorname{Obj}(\mathrm{X})=\left\{\mathrm{obj}_{1}(\mathrm{X}), \mathrm{obj}_{2}(\mathrm{X}), \ldots, \mathrm{obj}_{M}(\mathrm{X})\right\} \\
& \mathrm{X}=\left\langle x_{1}, x_{2}, \ldots, x_{D}\right\rangle \in R^{D} \\
& \text { s.t. }\left\{\begin{array}{l}
g_{i}(X) \leq 0, i=1,2, \ldots, k \\
h_{j}(X)=0, j=1,2, \ldots, l
\end{array}\right.
\end{aligned}
$$

Essentially, the above formula could be answered in two methods. One is the combination of fitness as one objective function. Therefore, the objective functions with appropriate and precise weight coefficients should be integrated together. The improved method of this article or the 2nd approach are based on sets of optimized Pareto. Assume that the $C$ is a probable region answer (sets of results of $x \in X$ that cover all linear and non-linear provisions) and $I=\{1,2, \ldots, k\}$. The $\mathrm{f} x * \in C$ will be an optimized Pareto if $\forall_{x \in C}$ is the $\forall_{i \in I} f_{i}(x *)=f_{i}(x)$ or $\exists_{i \in I} f_{i}(x *)<f_{i}(x) . U=\left\langle u_{1}, u_{2}, u_{3}, \ldots, u_{k}\right\rangle$ and $V=\left\langle v_{1}, v_{2}, v_{3}, \ldots, v_{k}\right\rangle$ are the vectors in the considered functions and $U$ will dominate for $V$ if and only if the $\forall_{i \in I}, u_{i} \leq v_{i}$ and $\exists i \in I$ when $U_{i}<V_{i}$. The optimized Pareto $\left(P^{*}\right)$ is a set of possible solutions if $P *=\left\{x \in C \mid \exists \mathrm{x}^{\prime} \in \mathrm{C}, \mathrm{f}\left(\mathrm{x}^{\prime}\right) \leq \mathrm{f}(\mathrm{x})\right\}$. In this work, the $\mathrm{PF}=\{\mathrm{f}(\mathrm{x}) \mid x \in P *\}$ as a Pareto front. The dominant count in a set of answers is equivalent to the numbers of solutions in the whole population that are dominant. The initial non- 
dominated front is equivalent to the sets of solutions whose domination count equals 0 . The 2nd non-dominated front is the sets of results whose dominant count equals zero and whose 1st non-dominated front is uncountable. Meanwhile, the total $i$ th of the non-dominant front $\psi_{i}$ is a set of solutions whose dominant count equals zero when the solutions are uncountable in front $\psi_{1}, \psi_{2}, \ldots, \psi_{i-1}$. Now, all the obtained solutions throughout the 1st front include the non-dominant front value 1. Naturally, the solutions throughout the second front consist of non-dominant value 2 . The mutuality approach is evaluated in guarantee the discovery of optimized solutions. In the method, the quantity of evaluated suitability for every aim function in level 1 is shared. Then, this quantity of suitability that is the little shared quantity in past functions is signed as a next Pareto front. Similarly, the method of sharing is done for the second level. Overall, this strategy will be continued until the quantity of suitability is joint in all levels. The possible equation for the shared approach (Share $\left.\left(d_{i j}\right)\right)$ is defined as follows:

$$
\begin{gathered}
\text { Share }\left(d_{i j}\right)= \begin{cases}1-\left(\frac{d_{i j}}{\mu_{\text {share }}}\right)^{2} & \text {, if } d_{i j}<\mu_{\text {share }} \\
0 & \text { otherwise }\end{cases} \\
d_{i j}=\sqrt{\sum_{a=1}^{P_{1}}\left(\frac{x_{s}^{i}-x_{s}^{j}}{x_{s}^{\max }-x_{s}^{\min }}\right)}
\end{gathered}
$$

where $p_{1}$ is the number of decisions made, $x_{s}$ is the quantity of the sth decision-making variable, and $i$ and $j$ are counters. $\mu_{\text {share }}$ is the highest acceptable distance between two variables, and its signing as the member niche indicates that this counter could be computed for the total $(N)$ population as follows:

$$
\text { Nichecount }_{i}=\sum_{j=1}^{N} \operatorname{Share}\left(d_{i j}\right) \text {. }
$$

Additionally, to enhance the convergence procedure between the non-dominated sets, the crowding distance is evaluated for evaluating the set of results [26]. This method is based on the computation of average distance, and an appropriate estimation of the density rate of better results between populations is achieved. In other words, this technique leads to the concentration of Pareto solutions. The entropy distribution for the $i$ th objective function could be expressed as follows:

$$
\begin{gathered}
E_{i j}=-\left[p l_{i j} \log _{2}\left(p l_{i j}\right)+p u_{i j} \log _{2}\left(p u_{i j}\right)\right] \\
p l_{i j}=\frac{d l_{i j}}{c_{i j}}, p u_{i j}=\frac{d u_{i j}}{c_{i j}}, c_{i j}=d l_{i j}+d u_{i j}
\end{gathered}
$$

where $d u_{i j}$ and $d l_{i j}$ are the current solutions with determined upper and limited restrictions of the $i$ th objective function. As expressed before, the optimized Pareto scale is the indicator that vector $x \in C$ is not present, which could modify the optimized Pareto vector. The fuzzy logic is implemented as a strategy in order to evaluate the appropriate cluster of their non-linear ones. The fuzzy decision-making function, which is presented by the membership function, should be able to substitute the accurate quantity of parameters.

\section{Simulation Test Systems}

In this article, the six thermal units considered as the case study are considered in different scenarios. The fuel cost coefficient of a generator, emission coefficient, the bound of the ramp rate, the predicted load demand profile for 24 , and other corresponding system data can be found in [27-29], and for the reader's convenience, they are presented in Table 1 and Figure 4. As presented in this figure, the first unit production is higher than the other units. The matrix of transmission loss constant of the six studied system units is shown in Equation (35). In total, the demand of each network is a combination of 
domestic, commercial, and industrial demands. The residential area has several controllable domestic devices such as a dish washing machine, washing machine, kettle, oven, and other domestic devices that could be simply managed during the demand shifting approach in comparison with other industrial and commercials demands. Hence, only the demand shift technique of DSM based on the next day is implemented for residential loads. During the implementation process of DSM, four cooperating levels with $5 \%, 10 \%, 15 \%$, and $20 \%$ of the whole habitable demand are evaluated. The electrical prices of the market are dedicated for total public facilities in each hour with the ToU tariff. In the mentioned test, the utilization of total controllable domestic devices is considered $2 \mathrm{~kW}$, but their pattern of electricity consumption is different. In the mentioned model, the maximized late steps of every controllable device based on their consumption lifestyle are dedicated. For example, two or three maximized delayed steps for necessary devices such as a kettle, oven, and hair dryer are evaluated in this work. In same approach, 12 maximum of delayed steps for less necessary devices such as a cloth dryer, iron, and vacuum cleaner are considered.

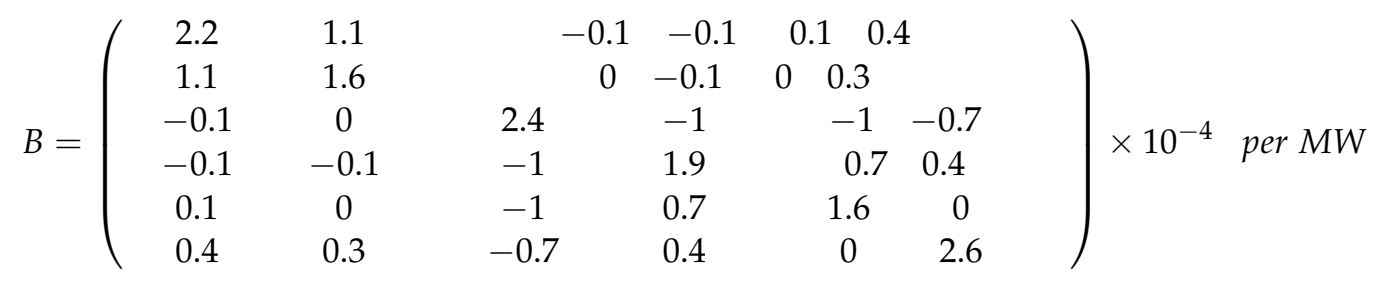

Table 1. The cost data of six thermal production units and their emission coefficients.

\begin{tabular}{|c|c|c|c|c|c|c|c|c|c|c|c|c|c|c|}
\hline \multirow[b]{2}{*}{$\begin{array}{c}\text { Thermal } \\
\text { Unites }\end{array}$} & \multicolumn{2}{|c|}{ Power Limits } & \multicolumn{5}{|c|}{ Fuel Cost Coefficients } & \multicolumn{5}{|c|}{ Emission Coefficients } & \multicolumn{2}{|c|}{ Ramp Rate Limits } \\
\hline & $\begin{array}{l}P^{\min } \\
(\mathrm{MW})\end{array}$ & $\begin{array}{l}P^{\max } \\
\text { (MW) }\end{array}$ & $a g$ & $b g$ & $c g$ & $d g$ & $e g$ & $\gamma g$ & $\beta g$ & $\alpha g$ & $\xi g$ & $\lambda g$ & $\begin{array}{c}\text { URg } \\
\text { (MW/h) }\end{array}$ & $\begin{array}{c}D R g \\
\text { (MW/h) }\end{array}$ \\
\hline Unit 1 & 50 & 200 & 0.00375 & 2 & 0 & 18 & 0.037 & 0.0649 & -0.05554 & 0.04091 & 0.0002 & 2.857 & 50 & 50 \\
\hline Unit 2 & 20 & 80 & 0.0175 & 1.75 & 0 & 16 & 0.038 & 0.05638 & -0.06047 & 0.02543 & 0.0005 & 3.333 & 16 & 16 \\
\hline Unit 3 & 15 & 50 & 0.0625 & 1 & 0 & 14 & 0.040 & 0.04586 & -0.05094 & 0.04258 & 0.000001 & 8 & 10 & 10 \\
\hline Unit 4 & 10 & 35 & 0.00834 & 3.25 & 0 & 12 & 0.045 & 0.0338 & -0.0355 & 0.05326 & 0.002 & 2 & 7 & 7 \\
\hline Unit 5 & 10 & 30 & 0.025 & 3 & 0 & 13 & 0.042 & 0.04586 & -0.05094 & 0.04258 & 0.000001 & 8 & 6 & 6 \\
\hline Unit 6 & 12 & 40 & 0.025 & 3 & 0 & 13.5 & 0.041 & 0.05151 & -0.05555 & 0.06131 & 0.000001 & 6.667 & 8 & 8 \\
\hline
\end{tabular}

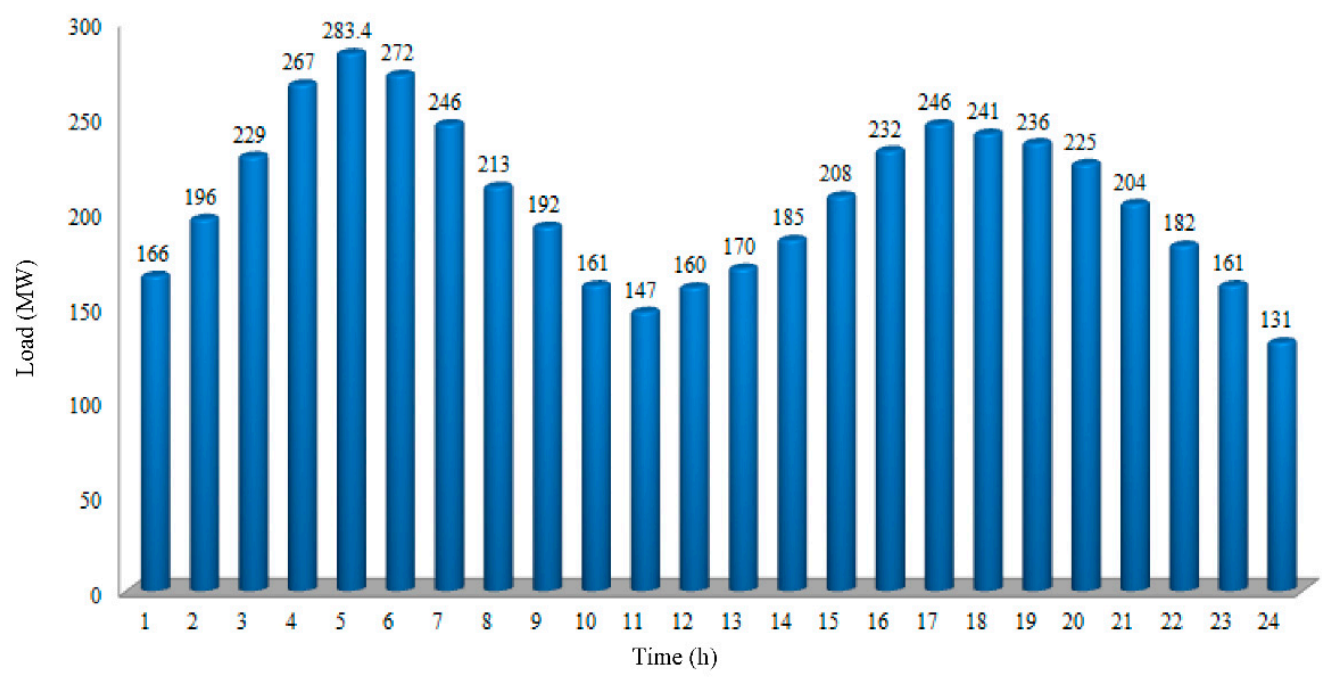

Figure 4. The load demand profile of $24 \mathrm{~h}$ from six test system units. 


\section{The Results of Simulation and Discussion}

In this article, the effects of DSM are studied over the public and production industry companies. The issue optimization of DSM and DEED is calculated in MATLAB software. In order to find the best answer, 30 different tests are conducted.

\subsection{The Effects of DSM on the Public Facility Side}

The main aim of this paper is analyzing the effects of DSM evaluation on the production side. Thus, the DSM is evaluated by minimization of the public electricity bill as the basic goal. Figure 5 presents the predicted load shape and the load curves after implementation of DSM with different levels of residential cooperation. It is obvious that an improved demand curve for higher cooperator levels is achieved. The public industry company has achieved interesting advantages, and this is because of the DSM evaluation that is presented in Figure 6a,b. By the obtained results of the DSM problem, the daily frugality of energy bills of the public industry company for participation levels are $5 \%$, $10 \%, 15 \%$, and $20 \%$ from those whole inhabitant demand are $\$ 363, \$ 731, \$ 1950$, and $\$ 1457$, respectively. Similarly, the peak load demand also for different levels of participation is $12.32,24.32,36.12$, and $49.01 \mathrm{MW}$, respectively.

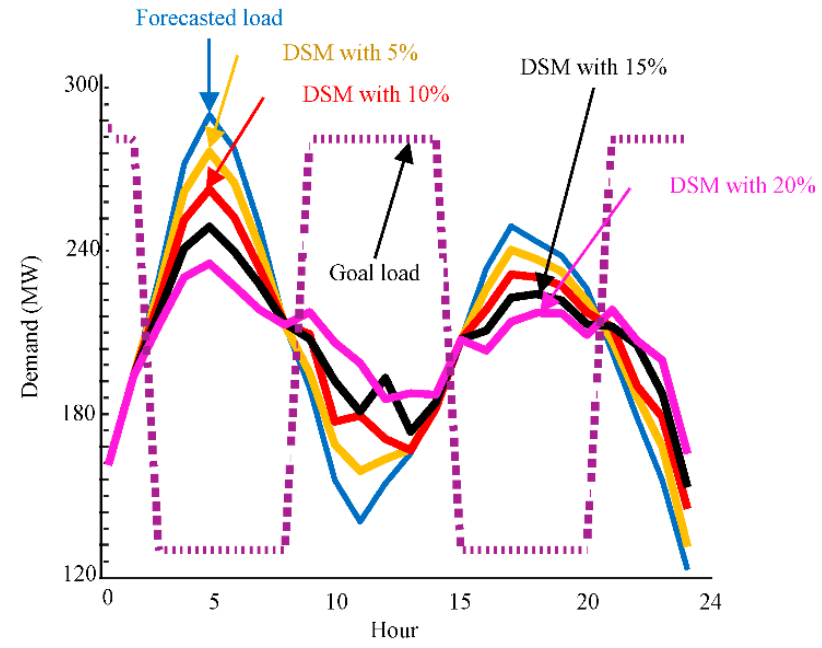

Figure 5. The curves of demand after DSM evaluation by various participation levels.
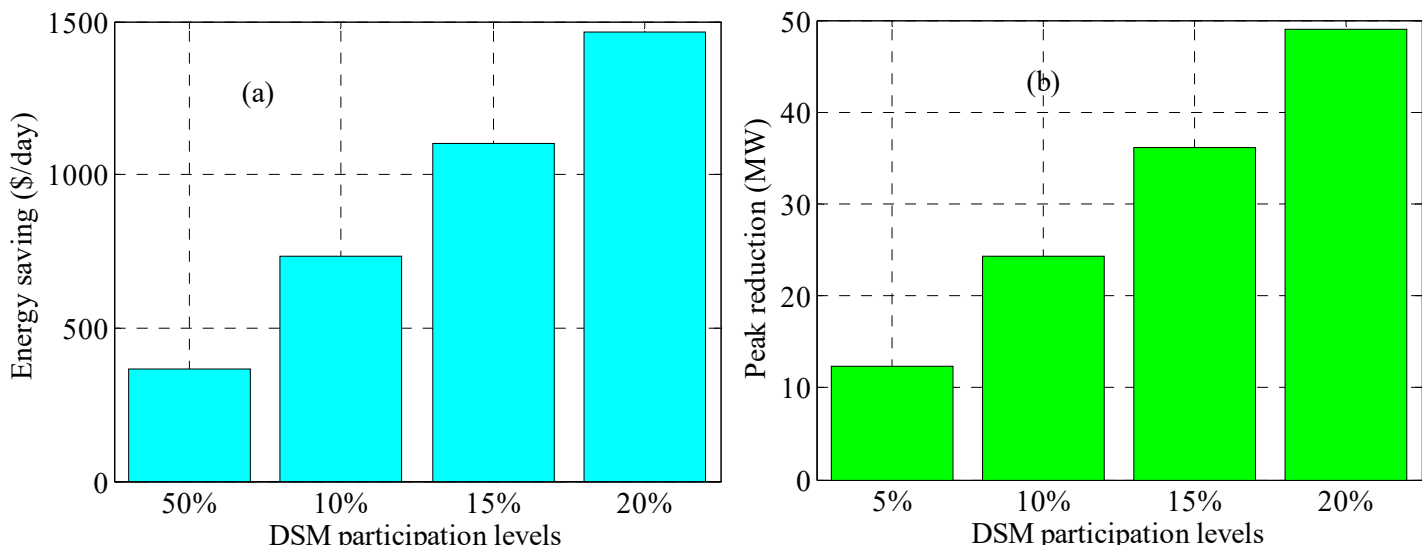

Figure 6. Frugality of public industry energy bill (a) and decline of peak load (b) by various levels of DSM participation.

In order to analyze the DSM effects in production, three test vases by various participation levels of DSM are considered. In the first and second test cases, the problems of dy- 
namic economical and emission dispatch are individually minimized by the DSM approach. Case 3 elaborates individually the suggested approach MODEED by the DSM model.

\subsection{Case 1: DSM Bundled with Dynamic Economic Dispatch}

The single dynamic economic dispatch is considered here as the first test case by considering the DSM effects over a fuel cell. For qualitative study, four different levels of participation are presented in DSM. In this approach, dynamic economic dispatch and DSM have been minimized simultaneity based on the suggested approach. The obtained numerical results are presented in Table 2 by including/excluding the DSM. Figure 7 demonstrates the convergence issues of DEED optimization including/excluding DSM. Results demonstrate the useful effects of DSM on electricity production through decreasing their fuel costs. In addition, it shows that the quantity of fuel production cost is minimized in different participation levels of DSM. For instance, DSM with the participation level of $20 \%$ has about a $7.5 \%$ drop in daily fuel cost in compared to the condition without DSM. Production companies can save a daily fuel cost equal to $\$ 91.5$, and this frugality is the result of DSM implementation.

Table 2. Dynamic economical dispatch with various participation levels of DSM.

\begin{tabular}{cccccc}
\hline $\begin{array}{c}\text { Participation } \\
\text { Level }\end{array}$ & $\begin{array}{c}\text { Without } \\
\text { DSM }\end{array}$ & $\begin{array}{c}\text { DSM with } \\
\mathbf{5 \%}\end{array}$ & $\begin{array}{c}\text { DSM with } \\
\mathbf{1 0} \%\end{array}$ & $\begin{array}{c}\text { DSM with } \\
\mathbf{1 5 \%}\end{array}$ & $\begin{array}{c}\text { DSM with } \\
\mathbf{2 0} \%\end{array}$ \\
\hline $\begin{array}{c}\text { Fuel cost } \\
\text { \$/day) }\end{array}$ & 13.554 & 13.513 & 13.469 & 13.456 & 13.413 \\
\hline $\begin{array}{c}\text { Emission } \\
\text { (tons/day) }\end{array}$ & 7.500 & 7.343 & 7.301 & 7.286 & 7.284 \\
\hline
\end{tabular}

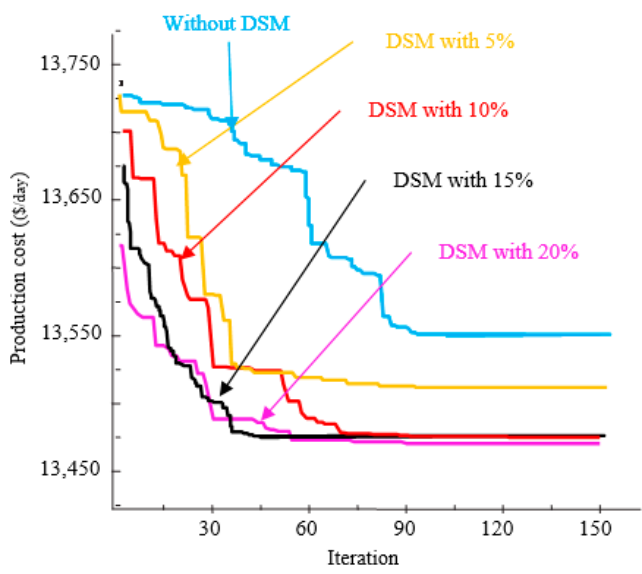

Figure 7. The convergence features of dynamic economic dispatch by various participation levels of DSM.

\subsection{Case 2: DSM Bundled with Dynamic Emission Distribution}

The single dynamic emission dispatch objective is considered in these test cases including the DSM. Obtained numerical analyses are presented in Table 3 by considering the dynamic emission distribution and including/excluding the DSM. Additionally, in this table, the proposed algorithm is compared with two other optimization models i.e., multi-objective genetic algorithm (NSGA) and multi-objective particle swarm optimization (MOPSO). Obtained results prove the validity and superiority of the proposed algorithm in minimum cost and emission as well. Figure 8 demonstrates the convergence features of dynamic emission dispatch including/excluding DSM. Regarding the obtained results, it is clear that there is a remarkable decrease in the emission level by implementation of DSM. For instance, in DSM, for the participation rate of $20 \%$, there is a daily 0.077 ton 
drop in the emission level compared to excluding DSM, which means 0.038 \$ / day i.e., $15.981-15.943=0.038$.

Table 3. Dynamic emission distribution by various levels of DSM participation.

\begin{tabular}{|c|c|c|c|c|c|c|}
\hline $\begin{array}{c}\text { Participation } \\
\text { Level }\end{array}$ & Method & Without DSM & DSM with $5 \%$ & DSM with $10 \%$ & DSM with $15 \%$ & DSM with $20 \%$ \\
\hline $\begin{array}{l}\text { Fuel cost } \\
\text { (\$/day) }\end{array}$ & \multirow{2}{*}{ NSGA } & 17.53 & 17.56 & 17.65 & 17.75 & 18.53 \\
\hline $\begin{array}{l}\text { Emission } \\
\text { (tons/day) }\end{array}$ & & 6.784 & 6.753 & 6.689 & 6.624 & 6.124 \\
\hline $\begin{array}{l}\text { Fuel cost } \\
(\$ / \text { day) }\end{array}$ & \multirow{2}{*}{ MOPSO } & 17.03 & 17.04 & 17.23 & 17.28 & 17.35 \\
\hline $\begin{array}{l}\text { Emission } \\
\text { (tons/day) }\end{array}$ & & 6.241 & 6.211 & 6.165 & 6.021 & 6.001 \\
\hline $\begin{array}{l}\text { Fuel cost } \\
\text { (\$/day) }\end{array}$ & \multirow{2}{*}{ Proposed } & 15.943 & 15.962 & 15.976 & 15.991 & 15.981 \\
\hline $\begin{array}{l}\text { Emission } \\
\text { (tons/day) }\end{array}$ & & 4.936 & 4.911 & 4.879 & 4.881 & 4.859 \\
\hline
\end{tabular}

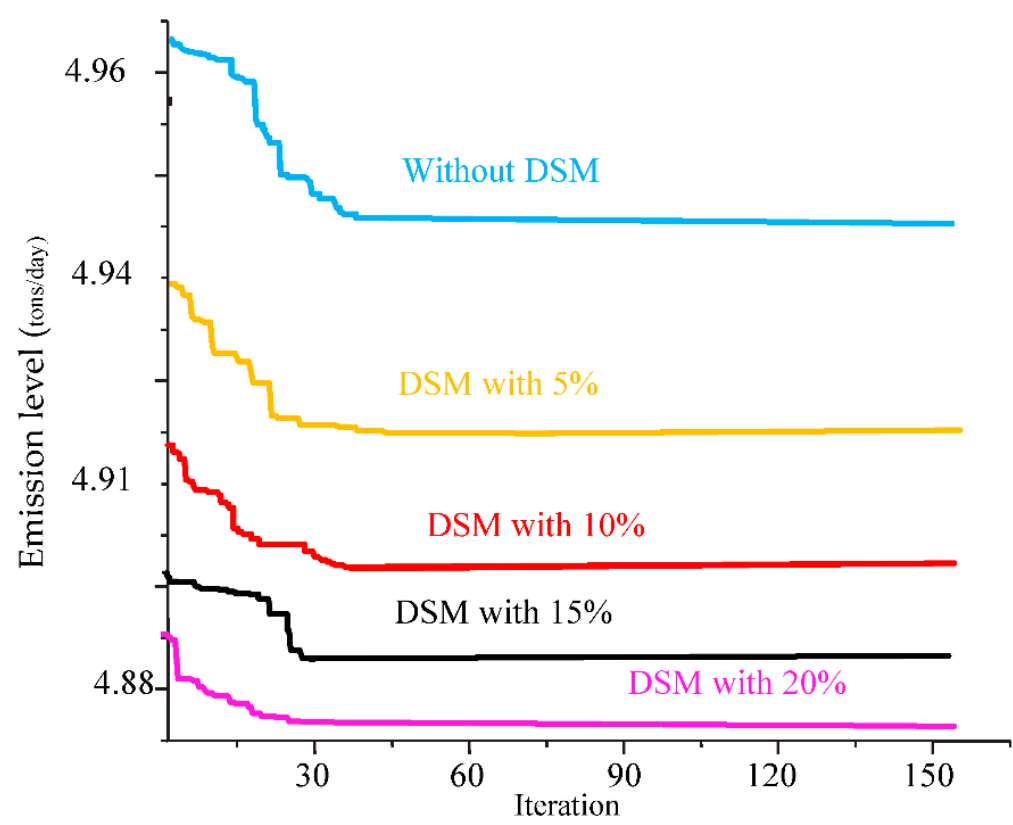

Figure 8. The convergence features of dynamic emission dispatch by different levels of DSM participation.

\subsection{Case 3: DSM Bundled with Economical and Emission Dispatch}

The DEED model by considering the DSM is considered in this test case through the MOABS algorithm. The obtained numerical analysis is presented in Figure 9 based on MODEED by considering various levels of DSM participation. In addition, Figure 10 shows the set of different Pareto values with different levels of DSM participation. The finest adaptive quantity of fuel cost and distribution using the fuzzy membership approach is found. 


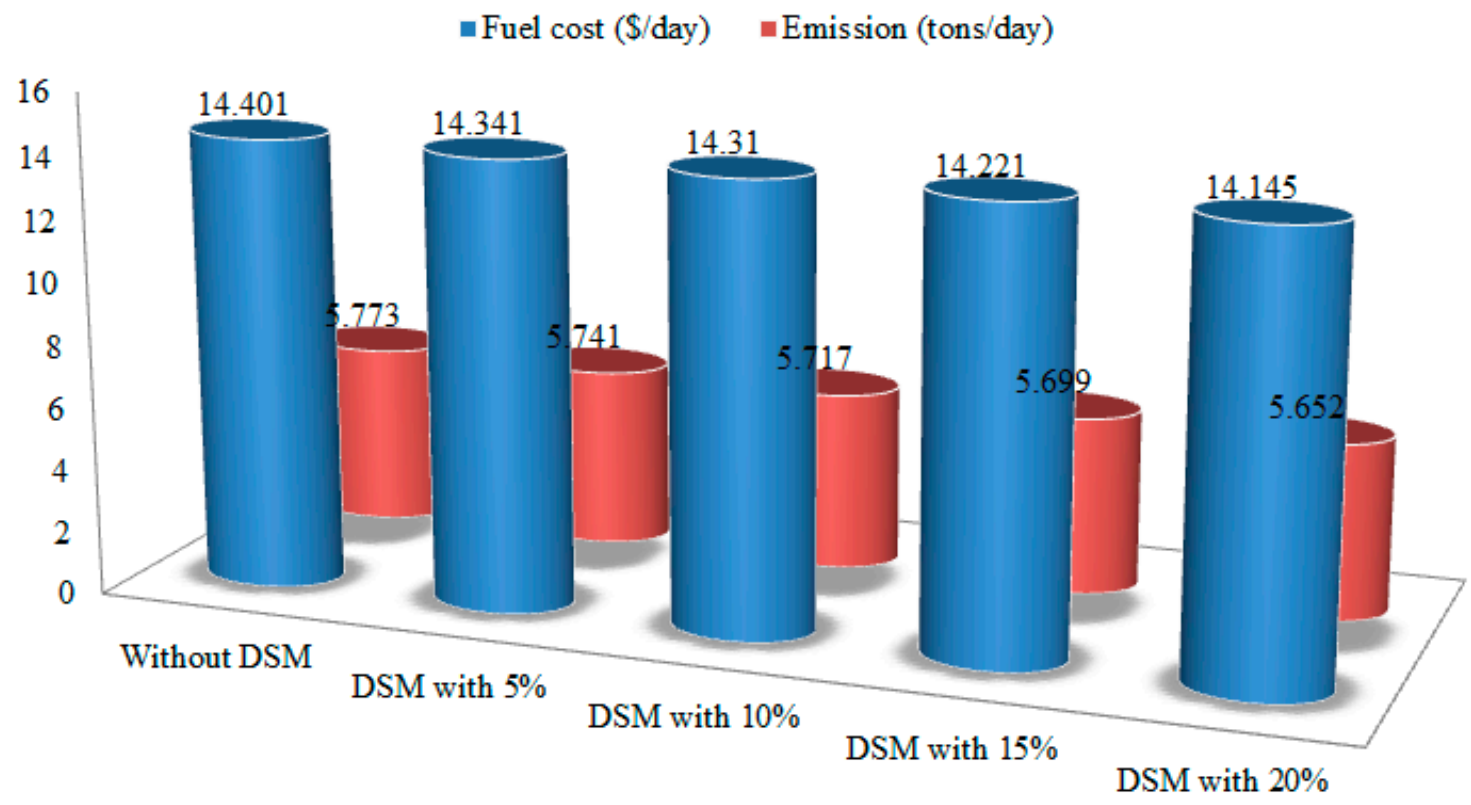

Figure 9. Dynamic economic and emission dispatch by various levels of DSM participation.

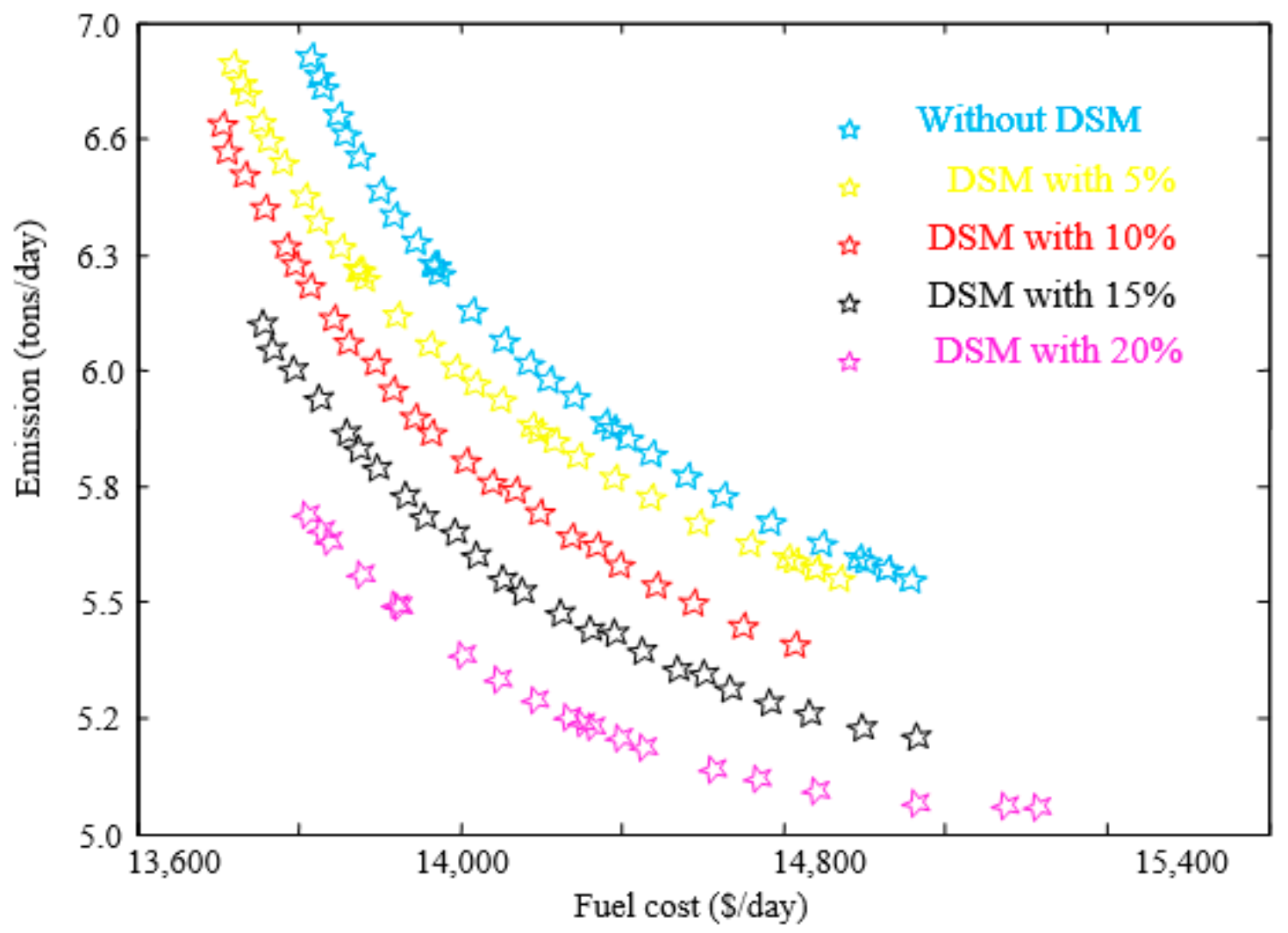

Figure 10. The sets of Pareto MODEED issues by various levels off DSM participation.

It is seen from the results that the proposed model has the ability to present the best solution compared to the single objective model for the similar participation level in DSM. For instance, the production companies could have saved a partial cost of daily fuel of $60.91 \%, 180 \%$, and $256 \%$ for participation levels of $5 \%, 10 \%, 15 \%$, and $20 \%$ of inhabitant demand, respectively. At this time, the production companies can decrease their sets of distribution levels. The decreases of distribution levels for different levels of participation are $0.032,0.056,0.074$, and 0.121 , respectively. The values of production units for timing 
programs of the proposed model in the participation level of DSM are achieved at $20 \%$ with or without DSM and are presented in Figure 11a,b.
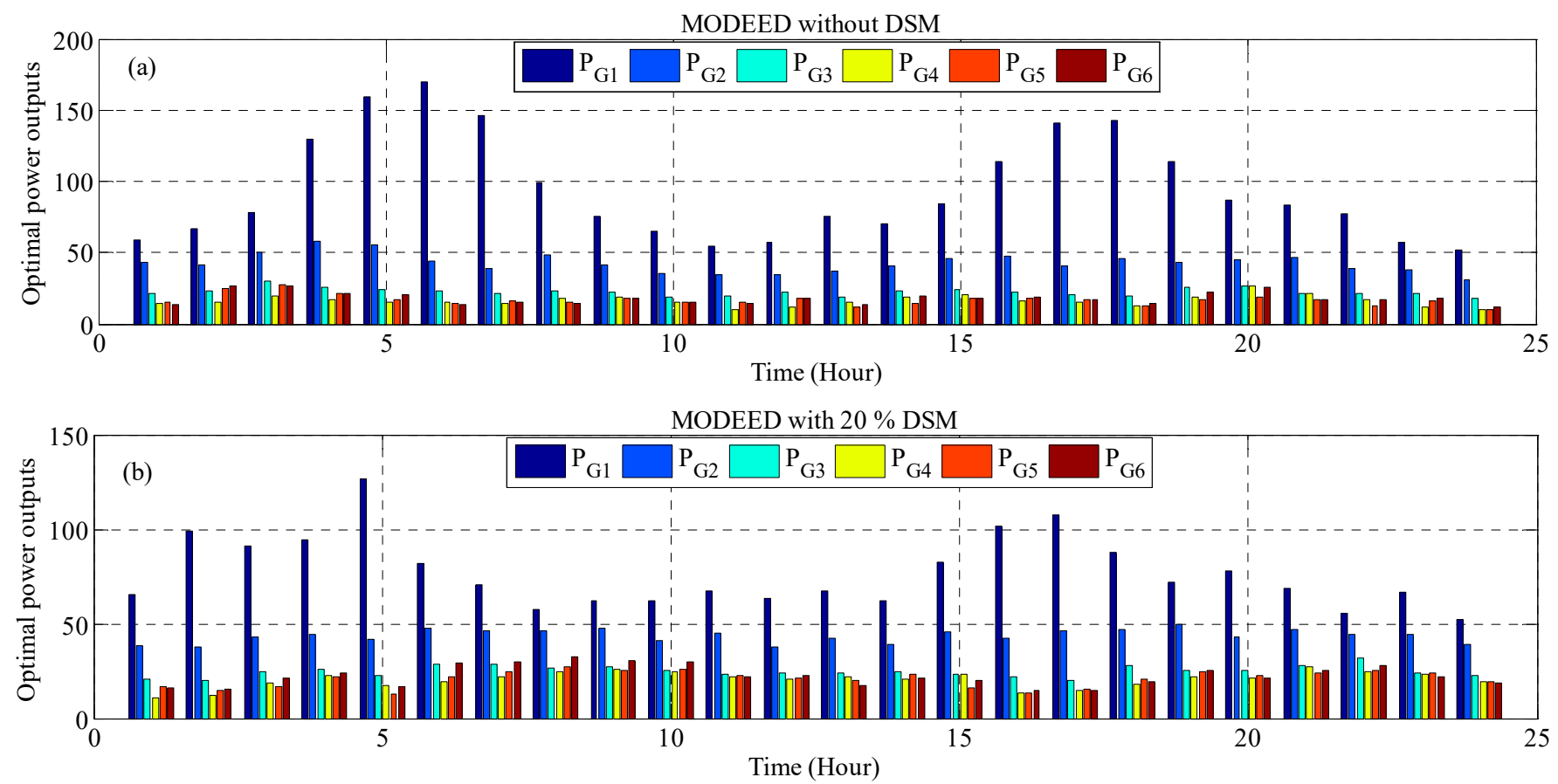

Figure 11. The output of optimized electricity of $24 \mathrm{~h}$ of generators, (a) in the present of DSM and (b) in the absence of DSM.

\subsection{Test Function for Multi-Objective Algorithm}

This section presents a new test system to evaluate the proposed multi-objective $\mathrm{ABC}$ algorithm and compare its results with other well-known multi-objective optimization algorithms. Therefore, the ZDT2 test function issue is selected [29]:

$$
\begin{gathered}
\min f_{1}(x)=x_{1} \\
\min f_{2}(x)=g(x)\left(1-\left(\frac{x_{1}}{g(x)}\right)^{2}\right) \\
g(x)=1+\frac{9}{n-1} \sum_{i=2}^{n} x_{i}^{2}, x_{1} \in[0,1], x_{i} \in[-1,1], i=2,3, \ldots, n
\end{gathered}
$$

If $n=30$, the problem of non-dominated Pareto front will be 219 in the regional Pareto front. To compare the proposed algorithm, consider two powerful MOPSO and NSGA-I algorithms with the same initial conditions such as the number of populations at 100 and a maximum iteration of 1000 . The best Pareto distribution for the proposed MOABC is arrived after 350, while this number for NSGA-I is 650, and for MOPSO, it is about 1000 iterations. The final Pareto solutions are shown in Figure 12. Figure 12 shows that the superiority of scattering solution points (Pareto front) is achieved through the proposed algorithm compared to the NSGA and MOPSO models. 


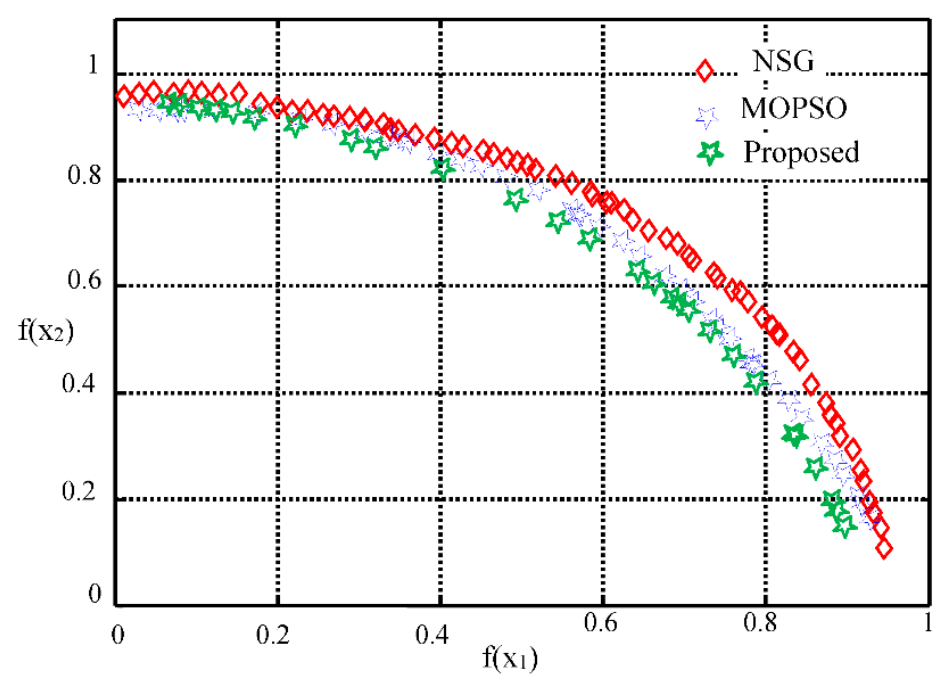

Figure 12. Pareto front of reformed ZDT2 issue by two aim functions.

\section{Conclusions}

This paper combined the MODEED with the DSM model in order to use the advantages of DSM in the public and production industry side. During the process of DSM, the load shift technique based on the next day for controlling residential loads and minimizing the public facilities energy bill energy is considered. Considering the regular manner of consumers, all essential household devices are included. The objective functions of emission and power dispatch were minimized for a system with six thermal units. Four various levels of inhabitant participation for investigating the impacts of DSM in the production side were considered. The multi-objective method is utilized for minimizing the MODEED based on a non-dominated arrangement. The simulation results demonstrated that the proposed model has the ability to present benefits for public companies and the production side. Furthermore, it is observed that the benefits of a $20 \%$ participation level are high.

Author Contributions: O.A.: Conceptualization, methodology, software, validation, formal analysis, investigation, resources, data curation, writing-original draft preparation, M.B.: writing-review and editing, visualization, supervision, project administration, funding acquisition. Both authors have read and agreed to the published version of the manuscript.

Funding: This work was supported in part by Collaborative Research Project (CRP) Grant of Nazarbayev University under grant no. 021220CRP0322, and in part by the Faculty Development Competitive Research Grant, Nazarbayev University, under grant no. 021220FD1251.

Institutional Review Board Statement: Not applicable.

Informed Consent Statement: Not applicable.

Conflicts of Interest: The authors declare no conflict of interest.

\section{References}

1. Coninx, K.; Deconinck, G.; Holvoet, T. Analysis of Activation Constraints and their Effect on Demand-Side Flexibility Allocations. In Proceedings of the 2018 IEEE PES Innovative Smart Grid Technologies Conference Europe (ISGT-Europe), Institute of Electrical and Electronics Engineers (IEEE), Sarajevo, Bosnia and Herzegovina, 21-25 October 2018; pp. 1-5.

2. Yilmaz, S.; Chambers, J.; Patel, M. Comparison of clustering approaches for domestic electricity load profile characterisation Implications for demand side management. Energy 2019, 180, 665-677. [CrossRef]

3. De Craemer, K.; Vandael, S.; Claessens, B.; Deconinck, G. An Event-Driven Dual Coordination Mechanism for Demand Side Management of PHEVs. IEEE Trans. Smart Grid 2013, 5, 751-760. [CrossRef]

4. Sobhani, S.O.; Sheykhha, S.; Azimi, M.R.; Madlener, R. Two-Level Distributed Demand-Side Management Using the Smart Energy Hub Concept. Energy Procedia 2019, 158, 3052-3063. [CrossRef]

5. van de Meerssche, B.; van Ham, G.; van Hertem, D.; Deconinck, G. Balancing renewables by demand side man-agement: Local and global potential. Int. J. Distrib. Energy Resour. 2013, 9, 383-397. 
6. Tang, R.; Wang, S.; Li, H. Game theory based interactive demand side management responding to dynamic pricing in price-based demand response of smart grids. Appl. Energy 2019, 250, 118-130. [CrossRef]

7. Essiet, I.; Sun, Y.; Wang, Z. Scavenging differential evolution algorithm for smart grid demand side management. Procedia Manuf. 2019, 35, 595-600. [CrossRef]

8. Kuiken, D.; Más, H.F. Integrating demand side management into EU electricity distribution system operation: A Dutch ex-ample. Energy Policy 2019, 129, 153-160. [CrossRef]

9. Craparo, E.; Sprague, J. Integrated supply- and demand-side energy management for expeditionary environmental control. Appl. Energy 2019, 233-234, 352-366. [CrossRef]

10. Lokeshgupta, B.; Sivasubramani, S. Multi-objective dynamic economic and emission dispatch with demand side management. Int. J. Electr. Power Energy Syst. 2018, 97, 334-343. [CrossRef]

11. Mellouk, L.; Boulmalf, M.; Aaroud, A.; Zine-Dine, K.; Benhaddou, D. Genetic Algorithm to Solve Demand Side Management and Economic Dispatch Problem. Procedia Comput. Sci. 2018, 130, 611-618. [CrossRef]

12. Logenthiran, T.; Srinivasan, D.; Shun, T.Z. Demand Side Management in Smart Grid Using Heuristic Optimization. IEEE Trans Smart Grid 2012, 3, 1244-1252. [CrossRef]

13. Ma, K.; Hu, G.; Spanos, C.J. Distributed Energy Consumption Control via Real-Time Pricing Feedback in Smart Grid. IEEE Trans. Control. Syst. Technol. 2014, 22, 1907-1914. [CrossRef]

14. Ma, K.; Hu, G.; Spanos, C.J. Energy Management Considering Load Operations and Forecast Errors with Application to HVAC Systems. IEEE Trans. Smart Grid 2018, 9, 605-614. [CrossRef]

15. Altinoz, O.T. The distributed many-objective economic/emission load dispatch benchmark problem. Swarm Evol. Comput. 2019, 49, 102-113. [CrossRef]

16. Alham, M.; Elshahed, M.; Ibrahim, D.; Zahab, E.E.D.A.E. A dynamic economic emission dispatch considering wind power uncertainty incorporating energy storage system and demand side management. Renew. Energy 2016, 96, 800-811. [CrossRef]

17. Dehnavi, E.; Abdi, H. Optimal pricing in time of use demand response by integrating with dynamic economic dispatch problem. Energy 2016, 109, 1086-1094. [CrossRef]

18. Zaman, F.; Elsayed, S.M.; Ray, T.; Sarker, R.A. Configuring two-algorithm-based evolutionary approach for solving dynamic economic dispatch problems. Eng. Appl. Artif. Intell. 2016, 53, 105-125. [CrossRef]

19. Aghaei, J.; Niknam, T.; Azizipanah-Abarghooee, R.; Arroyo, J.M. Scenario-based dynamic economic emission dispatch considering load and wind power uncertainties. Int. J. Electr. Power Energy Syst. 2013, 47, 351-367. [CrossRef]

20. Qiao, B.; Liu, J. Multi-objective dynamic economic emission dispatch based on electric vehicles and wind power integrated system using differential evolution algorithm. Renew. Energy 2020, 154, 316-336. [CrossRef]

21. Zou, Y.; Zhao, J.; Ding, D.; Miao, F.; Sobhani, B. Solving dynamic economic and emission dispatch in power system integrated electric vehicle and wind turbine using multi-objective virus colony search algorithm. Sustain. Cities Soc. 2021, 67, 102722. [CrossRef]

22. Gul, R.N.; Ahmad, A.; Fayyaz, S.; Sattar, M.K.; Haq, S.S.U. A Hybrid Flower Pollination Algorithm with Sequential Quadratic Programming Technique for Solving Dynamic Combined Economic Emission Dispatch Problem. Mehran Univ. Res. J. Eng. Technol. 2021, 40, 371-382. [CrossRef]

23. Li, X.; Wang, W.; Wang, H.; Wu, J.; Fan, X.; Xu, Q. Dynamic environmental economic dispatch of hybrid renewable energy systems based on tradable green certificates. Energy 2020, 193, 116699. [CrossRef]

24. Kaboli, A.; Abdullah, S.H.; Alqallaf, K. Solving non-convex economic load dispatch problem via artificial cooperative search algorithm. Expert Syst. Appl. 2019, 128, 14-27. [CrossRef]

25. Armaghani, S.; Amjady, N.; Abedinia, O. Security constrained multi-period optimal power flow by a new enhanced artificial bee colony. Appl. Soft Comput. 2015, 37, 382-395. [CrossRef]

26. Abedinia, O.; Wyns, B.; Ghasemi, A. Robust fuzzy PSS design using ABC. In Proceedings of the 2011 10th International Conference on Environment and Electrical Engineering, Institute of Electrical and Electronics Engineers (IEEE), Rome, Italy, 8-11 May 2011; pp. 1-4.

27. Niknam, T.; Narimani, M.; Aghaei, J.; Azizipanah-Abarghooee, R. Improved particle swarm optimisation for multi-objective optimal power flow considering the cost, loss, emission and voltage stability index. IET Gener. Transm. Distrib. 2012, 6, 515. [CrossRef]

28. Simon, S.; Padhy, N.; Anand, R. Ant colony system based unit commitment problem with Gaussian load distribution. In Proceedings of the 2006 IEEE Power Engineering Society General Meeting, Montreal, QC, Canada, 16 October 2006; Volume 8. [CrossRef]

29. Niknam, T.; Narimani, M.R.; Abarghooee, R.A. A new hybrid algorithm for optimal power flow considering pro-hibited zones and valve point effect. Energy Convers Manag. 2012, 58, 197-206. [CrossRef] 